\title{
Food for Comfort: A Short Narrative Review on Eating Behaviour and Obesity
}

Amiraa Ali Mansor, Angela Chan Nguk Fong, Mohammad Hatta Safuddin, Muhammad Fadhil Bin Ritin

To Link this Article: http://dx.doi.org/10.6007/IJARBSS/v11-i11/11409

DOI:10.6007/IJARBSS/v11-i11/11409

Received: 05 September 2021, Revised: 30 September 2021, Accepted: 20 October 2021

Published Online: 11 November 2021

In-Text Citation: (Mansor et al., 2021)

To Cite this Article: Mansor, A. A., Fong, A. C. N., Safuddin, M. H., \& Ritin, M. F. Bin. (2021). Food for Comfort: A Short Narrative Review on Eating Behaviour and Obesity. International Journal of Academic Research in Business and Social Sciences, 11(11), $783-788$.

Copyright: (c) 2021 The Author(s)

Published by Human Resource Management Academic Research Society (www.hrmars.com)

This article is published under the Creative Commons Attribution (CC BY 4.0) license. Anyone may reproduce, distribute, translate and create derivative works of this article (for both commercial and non-commercial purposes), subject to full attribution to the original publication and authors. The full terms of this license may be seen

at: http://creativecommons.org/licences/by/4.0/legalcode

Vol. 11, No. 11, 2021, Pg. $783-788$

Full Terms \& Conditions of access and use can be found at http://hrmars.com/index.php/pages/detail/publication-ethics 


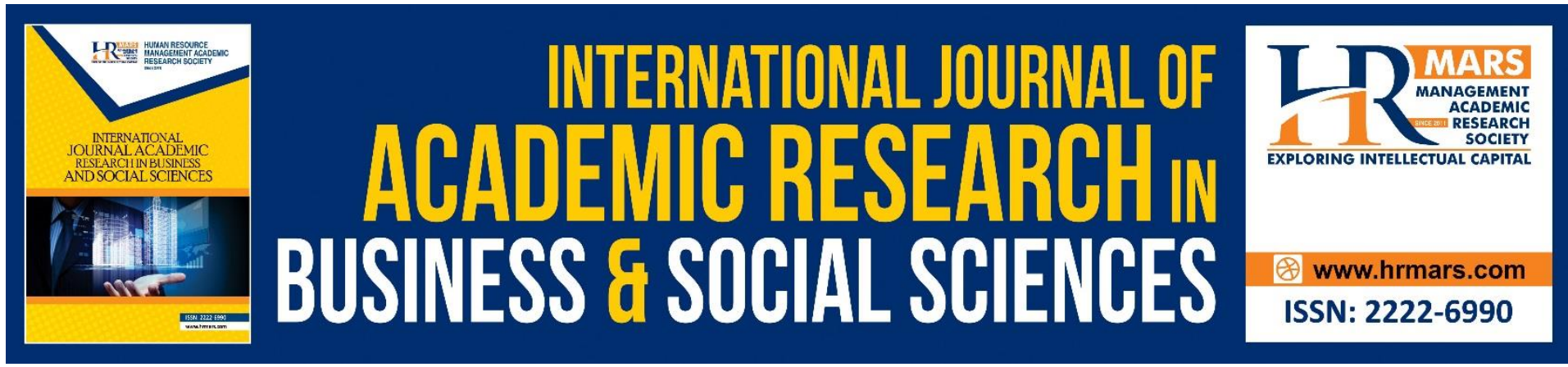

\title{
Food for Comfort: A Short Narrative Review on Eating Behaviour and Obesity
}

\author{
Amiraa Ali Mansor ${ }^{1,2}$ Angela Chan Nguk Fong², Mohammad \\ Hatta Safuddin ${ }^{2}$, Muhammad Fadhil Bin Ritin ${ }^{3}$ \\ ${ }^{1}$ Cluster of Education and Social Sciences, Open University Malaysia, ${ }^{2}$ Faculty of Education \\ and Social Sciences, University Selangor, ${ }^{3}$ Faculty of Human Development, University \\ Pendidikan Sultan Idris \\ Corresponding Author Email address: amiraa_alimansor@oum.edu.my
}

\begin{abstract}
The World Health Organization revealed that worldwide obesity has tripled, with 1.9 billion adults categorised as overweight and 650 million adults classified as obese. The increase in body mass presents public health challenges due to the poor health outcomes of those who are overweight and obese. A computerised literature search was performed using Scopus, PubMed and Google Scholar with keywords 'eating behaviours, 'eating habits', 'food consumption', 'food choice', 'food preference, 'body mass index', 'overweight' and 'obesity'. Titles and abstracts of potentially relevant articles published in English between 2010 and 2020 were screened. The objective of this review was to identify the contribution of eating behaviour on obesity among university students. Studies were included solely based on relevance to the research review objective. The included papers were grouped based on content and methodology of cross-sectional studies which examined the relationship between eating behaviour and obesity among university students. The reviews on past research focused on eating behaviour and obesity among university students since an abundance of literature demonstrates that most students gain weight during the university life. Determining the extent to which psychological aspects contribute to the increasing worldwide obesity pandemic is critical for improving interventions, policies and practices.
\end{abstract}

\section{Introduction}

The importance of food is obvious, as it is essential for survival. Individuals' food consumption and selection on a daily basis are usually affected by their own motivations (Phan \& Chambers, 2016) and environments (Funk et al., 2021). Healthy eating behaviour by consuming nutrient-dense food is crucial as it affects individuals' well-being and lifestyle rather than merely helping them survive day-to-day life. In contrast, unhealthy eating behaviours such as consuming nutrient-deficient food, skipping meals, and a lack of timely diet are understood to cause nutritional deficiencies and various health problems (Kabir et al., 2018).

Nowadays, food is no longer solely a source of survival. It has increasingly become a matter of concern due to the possibility of diseases resulting from unhealthy eating behaviour. The 
prime reason for such concern is the growing epidemic of obesity resulting from the obesogenic environment with plenty of cheap and high-calorie foods available at any place, any time (Llewellyn, 2018). It is possible that consuming a large amount of unhealthy food, like fast food or junk food, and liquid calories, such as sweetened beverages and sugary soft drinks, is detrimental to one's health since it will result in obesity which in turn contributes to serious disease, reduced quality of life and greater risk of mortality (Upadhyay et al., 2018). Obesity is a serious health issue that goes beyond an attractive physical appearance. It is a life-threatening medical condition wherein an individual has excess body fat and a body mass index (BMI) greater than or equal to $30 \mathrm{~kg} / \mathrm{m} 2$ (Shabana \& Hasnain, 2016). More concerning, in 2016, the World Health Organization revealed that worldwide obesity has tripled, with 1.9 billion adults categorised as overweight and 650 million adults classified as obese (World Health Organisation, 2016).

A high number of children and adolescents are also affected, with 41 million children under the age of 5 and 340 million of those aged 5 to 19 years who had become overweight or developed obesity (World Health Organisation, 2016). The increase in body mass presents public health challenges due to the poor health outcomes of those who are overweight and obese. Obese individuals have to deal with various health problems, such as diabetes, hypertension and heart disease, that may lead to poorer health conditions and shorter life expectancies than normal-weight individuals (Nagai et al., 2012).

\section{Scope And Methodology of the Review}

The bibliographic search strategy focused on articles published in peer-reviewed, English language journals was completed by a single researcher and the results were reviewed by the other members of the research team. A computerised literature search was performed using Scopus, PubMed and Google Scholar with keywords 'eating behaviours, 'eating habits', 'food consumption', 'food choice', 'food preference, 'body mass index', 'overweight' and 'obesity'. Titles and abstracts of potentially relevant articles published in English between 2010 and 2020 were screened. The studies were included solely based on relevance to the research aim to understand the context of current of eating behaviour that underlie the development of obesity in university students. The included papers were grouped based on content and methodology of cross-sectional studies which examined the relationship between eating behaviour and obesity among university students.

\section{Obesity-A Multifactorial Etiology Other Than Genetic}

The underlying cause of obesity is multifaceted in etiology, involving genetic, cognitive, behavioural and environmental factors (Todd et al., 2015). Understanding what causes obesity is becoming even more crucial in light of the current rise in its prevalence. At the most basic level, an individual will only become obese if their calorie intake exceeds their calorie expenditure over an extended period of time, resulting in a chronic positive balance in the body. There are vast amounts of research that have been conducted pertaining to the influences of genetics on obesity. The concept of a hereditary factor to obesity has been recognised for a long time, with evidence of familial variation in obesity being published as early as 1923 (Elks et al., 2012). However, although heredity plays a role in obesity, genes are not destiny, and a healthy environment could help offset individuals' genetic susceptibilities to obesity (Kim, 2020).

Today, much concern has been given to the "nurture" aspects of obesity, including psychological aspects, to understand its onset. Determining the extent to which psychological 
aspects contribute to the increasing worldwide obesity pandemic is critical for improving interventions, policies and practices. This overview of past research provides a summary of the current evidence, emphasising determining the relative relevance of nurture issues in particular on eating behaviours contributing to the development of obesity.

The reviews on past research focused on eating behaviour and obesity among university students since an abundance of literature demonstrates that most students gain weight during the first year of university life (Beaudry et al., 2019). The eating behaviour may evolve over the university years due to less parental involvement (Fedewa et al., 2014). Furthermore, the failure of university students to cope with the new environment and associated stressors can lead to unhealthy eating behaviours such as excessive alcohol consumption and stressrelated over-eating (Leonard et al., 2015). The contribution of eating behaviour to the onset of obesity among university students is discussed in the following sections.

\section{Nurture: The Contribution of Eating Behaviour Influences on Obesity}

Unhealthy eating behaviours among undergraduate university students have been linked to the excessive consumption of calorie-dense foods, which leads to obesity (Kabir et al., 2018). In Iraq, for example, a study was undertaken to determine the relationship between being overweight or obese and eating behaviour among a total of 111 university students. Among the various eating behaviours, high-calorie-dense foods are thought to be one cause of obesity, particularly when large portion sizes are consumed regularly. This study also revealed that behaviours including a diet high in fatty foods, snacking, and eating quickly have all been linked to an increased prevalence of obesity (Sahib, 2016).

Furthermore, a study conducted by Yousif et al (2019) in Sudan involving 216 medical students revealed a significant link between eating behaviours and obesity similar to previous work. Most of the research participants reported unhealthy eating behaviours, where nearly half of the students were uncontrolled eaters (45.8\%) and emotional eaters (25.5\%).

Another study was undertaken to identify eating behaviour involving fast food consumption among female university students in Saudi Arabia. The findings revealed a strong link between fast food consumption frequency and BMI. $56 \%$ of the students who eat fast food two or more times a week were obese, putting these students at risk for many chronic diseases related to high fat intake (Al-Otaibi \& Basuny, 2015). The same results were found in research involving 398 students in Alexandria, Egypt, conducted to determine the incidence of obesity and their eating behaviours. Students completed a self-reported questionnaire on their eating, drinking and smoking behaviours, as well as their weight and height. The results indicated that $28.9 \%$ of the students were obese, while $11.8 \%$ were overweight. The study discovered that obesity and being overweight were prevalent among the participants due to the detrimental eating behaviours of irregular and infrequent meals, low vegetable consumption and frequent snacking (Genena \& Salama, 2017).

\section{Conclusion}

The research review shows how university students engaged in unhealthy eating behaviours, such as increased consumption of sugar-sweetened beverages, junk foods that are poor in nutrients and fast food, which may be due to a lack of parental monitoring and greater autonomy over food intake. The scenario of a decrease in healthy eating behaviour helps us to understand the current state of universities students' physical well-being and why most university students fail to meet the standard dietary recommendations. 
Moreover, many obesity research scientists agree that the increasing number of people with obesity during the past few decades is because of major changes in their surroundings (Hurt et al., 2010). Lifestyle choices around what a person's eating behaviours are like and their level of physical fitness have an important role in causing obesity. Surprisingly, many individuals still turn to food and indulge in unhealthy eating behaviour as a coping technique to deal with situations such as stress, boredom, worry, happiness, sadness or anger. Consequently, they devour a massive amount of food in a short period of time that the normal person would not consume in the same length of time, eventually resulting in being overweight, obesity and other diseases (Gan et al., 2018).

\section{Limitation}

This review summarises the literature on eating behaviour influences on obesity among university students. A short narrative approach was favoured to understand the issues over a systematic search strategy. While this has benefits in permitting a breadth of evidence to be included, the absence of a systematic search strategy introduces the potential for bias in the selection of studies. There is substantial literature on this topic, and it is recommended to read it widely to gain a fuller picture of the different approaches that have been taken to study the causes of the obesity epidemic and the various strategies undertaken in an effort to curtail the problem.

\section{Acknowledgements}

All authors contributed equally to the concept and writing of this paper. There are no conflicts of interest.

\section{References}

Al-Otaibi, H. H., \& Basuny, A. M. (2015). Fast food consumption associated with obesity/overweight risk among university female student in Saudi Arabia. Pakistan Journal of Nutrition, 14(8), 511-516. https://doi.org/10.3923/pjn.2015.511.516

Beaudry, K. M., Ludwa, I. A., Thomas, A. M., Ward, W. E., Falk, B., \& Josse, A. R. (2019). Firstyear university is associated with greater body weight, body composition and adverse dietary changes in males than females. PLOS ONE, 14(7), 1-19. https://doi.org/10.1371/journal.pone.0218554

Elks, C. E., Hoed, M. den, Zhao, J. H., Sharp, S. J., Wareham, N. J., Loos, R. J. F., \& Ong, K. K. (2012). Variability in the heritability of body mass index: A systematic review and metaregression. Frontiers in Endocrinology, 3(FEB), 1-16. https://doi.org/10.3389/fendo.2012.00029

Fedewa, M. V., Das, B. M., Evans, E. M., \& Dishman, R. K. (2014). Change in weight and adiposity in college students: A systematic review and meta-analysis. American Journal of Preventive Medicine, 47(5), 641-652. https://doi.org/10.1016/j.amepre.2014.07.035

Funk, A., Sütterlin, B., \& Siegrist, M. (2021). Consumer segmentation based on Stated environmentally-friendly behavior in the food domain. Sustainable Production and Consumption, 25, 173-186. https://doi.org/10.1016/j.spc.2020.08.010

Gan, W. Y., Mohamad, N., \& Law, L. S. (2018). Factors associated with binge eating behavior among Malaysian adolescents. Nutrients, 10(1). https://doi.org/10.3390/nu10010066

Genena, D. M., \& Salama, A. A. (2017). Obesity and Eating Habits among University Students in Alexandria, Egypt: A Cross Sectional Study. World Journal of Nutrition and Health, October. https://doi.org/10.12691/jnh-5-3-1 
Hurt, R. T., Kulisek, C., Buchanan, L. A., \& McClave, S. A. (2010). The obesity epidemic: Challenges, health initiatives, and implications for gastroenterologists. Gastroenterology and Hepatology, 6(12), 780-792.

Kabir, A., Miah, S., \& Islam, A. (2018). Factors influencing eating behavior and dietary intake among resident students in a public university in Bangladesh: A qualitative study. PLoS ONE, 13(6), 1-17. https://doi.org/10.1371/journal.pone.0198801

Kim, J. (2020). Are genes destiny? Exploring the role of intrauterine environment in moderating genetic influences on body mass. American Journal of Human Biology, 32(3), 1-14. https://doi.org/10.1002/ajhb.23354

Leonard, N. R., Gwadz, M. V., Ritchie, A., Linick, J. L., Cleland, C. M., Elliott, L., \& Grethel, M. (2015). A multi-method exploratory study of stress, coping, and substance use among high school youth in private schools. Frontiers in Psychology, 6(July), 1-16. https://doi.org/10.3389/fpsyg.2015.01028

Llewellyn, C. H. (2018). Genetic susceptibility to the "obesogenic" environment: The role of eating behavior in obesity and an appetite for change. American Journal of Clinical Nutrition, 108(3), 429-430. https://doi.org/10.1093/ajcn/nqy210

Nagai, M., Kuriyama, S., Kakizaki, M., Ohmori-Matsuda, K., Sone, T., Hozawa, A., Kawado, M., Hashimoto, S., \& Tsuji, I. (2012). Impact of obesity, overweight and underweight on life expectancy and lifetime medical expenditures: The Ohsaki Cohort Study. BMJ Open, 2(3). https://doi.org/10.1136/bmjopen-2012-000940

Phan, U. T. X., \& Chambers, E. (2016). Motivations for choosing various food groups based on individual foods. Appetite, 105, 204-211. https://doi.org/10.1016/j.appet.2016.05.031

Shabana, \& Hasnain, S. (2016). Obesity, More than a 'Cosmetic' Problem. Current Knowledge and Future Prospects of Human Obesity Genetics. Biochemical Genetics, 54(1), 1-28. https://doi.org/10.1007/s10528-015-9700-2

Todd, A. S., Street, S. J., Ziviani, J., Byrne, N. M., \& Hills, A. P. (2015). Overweight and obese adolescent girls: The importance of promoting sensible eating and activity behaviors from the start of the adolescent period. International Journal of Environmental Research and Public Health, 12(2), 2306-2329. https://doi.org/10.3390/ijerph120202306

Upadhyay, J., Farr, O., Perakakis, N., Ghaly, W., \& Mantzoros, C. (2018). Obesity as a Disease. Medical Clinics of North America, 102(1), 13-33. https://doi.org/10.1016/j.mcna.2017.08.004

World Health Organisation. (2016). WHO | Obesity and overweight. In WHO. World Health Organization. http://www.who.int/mediacentre/factsheets/fs311/en/index.html

Yousif, M. M., Kaddam, L. A., \& Humeda, H. S. (2019). Correlation between physical activity, eating behavior and obesity among Sudanese medical students Sudan. BMC Nutrition, 5(1), 1-8. https://doi.org/10.1186/s40795-019-0271-1 